utterly destroyed with their contemporaries by the same cause, but merely migrated to regions more suited to them, as the climate and other conditions of this country changed.

Exhibits. - Bones, teeth, and part of the tusks of mammoth, and associated flint implements from Southall. A flint implement from the lacustrine (?) bed at the Mount, Ealing (I90 to 200 O.D.) (See the author's paper, Proceedings Geologists' As-ociation, vol. $x$. No. 4). A flint apparently worked by man from the Weybourn Crag, beneath the "Forest bed" near Cromer. A Palæolithic scraper found on the beach near Cromer, \&c.

\section{THE POISONOUS SNAKES OF THE BOMBAY PRESIDENCY.}

$A T$ a recent meeting of the Bombay Natural History Society, a paper was read by the Honorary Secretary. Mr. H. M. Phipson, on the "Poisonous Snakes of the Hombay Presidency." $\mathrm{He}$ produced for inspection specimens of the following poisonous snakes, all of them having been killed in the Presidency of Bombay.

Colubrine.--(1) Ophiophagus clats; (2) Naga tripudians, (3) Bungarus arcuatus; (4) Callophis trimaculatus; (5) Callophis nigre:cens.

Viperine. - (6) Daboic elegans; (7) Echis carinata; (8) Trimeresurus anamallenis; (9) Hypnale nepa.

With regard to the first species, the Ophiophagus elaps, it is perhaps the largest poisonous snake in the world, sometimes measuring over 15 feet. It is also called the "king cobra" or "hamadryad," and is not very common, though widely diffused, being found in the Andamans, the Philippines, Borneo, Java, and Sumatra. On account of expanding a "hood," it is frequently misiaken for the cobra, but the head-shields of the hamadryad differ very much from those of the cobra. The second species, Naga tripudians, or cobra, is found all over India, and up to the height of 8000 feet in the Himalayas. There are many varieties, differing in colour and marking, to which the natives give different names, thinking them distinct species; but in such matters the native knowledge is not very extensive. Thus they believe that all the hooded cobras are females, and that the males are harmless. What they call the male is in reality only the common Indian rat snake (Ptyas mucosus). They also state that the rat snake is proof against the poison of the cobra. But this is not the case. Last year the young ones hatched in the Society's rooms attacked a small Malay python put into their cage, when they were only a few days old, and bit at it viciously, and the python died in a few hours after its removal to another cage. Once a year, during the rainy season, the cobra lays from twelve to twenty eggs. In one specimen shown by Mr. Phipson, the young one is seen just as it is emerging from the egg. The tooth with which it cuts its way out is shed as soon as it has served its purpose. IVhen born, the young cobras measured about $7 \frac{1}{1}$ inches long, and were very fat ; but at the end of a few months they were about 9 inches in length, but had lost all their plumpness. It is very remarkable that the original nutriment got out of the egg should be able to sustain them so long. Un account of its timidity and the great ease with which it can be tamed, it is the only snake with which the snakecharmers will have anything to do. By attracting its attention with one hand, it may be easily seized round the body with the other ; and so long as the hand or any other object is kept moving before its eyes, it will never turn to bite the hand that holds it. This is the simple fact the knowledge of which the charmers turn to such advantage in their well-known performances. The snake is taken from its basket, and a slight stroke across the back brings it at once into a defensive attitude. The constant motion of the musical instrument before the snake keeps it watchful and erect, and not the music produced. As a matter of fact, snakes have no external ears, and it is extremely doubtful whether the cobra hears the music at all. The charmers say that the adder of the East, the Daboia, has no ear for music, because they cannot operate on it as they do on the cobra. It is rather interesting to note that this has been the belief since David's time at least- "like the deaf adder that stoppeth her ear; which will not hearken to the voice of charmers." (3) The krait (Bungarus arcuatus) is an exceedingly poisonous snake, and is quite common in nearly every part of India. One specimen taken in the Bombay Presiclency contained a "brown tree snake" (Dipsas gokool) and in another specimen was found a Ptyas mucosus, thus showing that this species eats snakes. The common Lycodsn aulicus, one of the non-poisonous snakes, is very much like the krait, but they can be distinguished by the presence in the krait of large hexagonal scales down the centre of the back. (4) The Callophis trimaculatus has no popular name. It is undoubtedly poisonous, and lives on other snakes, very likely the Calamariæ. (5) Callothis nigrescens, which grows to about 4 feet in length, is black in the upper parts and red in the lower.

(6) The first class of the Viperine snakes is the Dabria clegans called by Europeans in India the Chain Viper and in Ceylon the Tic Polonga The fangs are very long, and for this reasun, together with its fierceness, it is the most dreaded snake in India. Its poison acts differently from that of the cobra. Its tenacity of life is really wonderful, it having been known to live for a whole year without food. The length of this snake rarely exceeds 5 feet. (7) The Echis carinata and the last-named class are the only true vipers in India. The harmless "brown tree snake" (Dipsas gokool) is frequently confused with the Echis carinata, but they are easily distinguished by the scales on the head of the latter, while the Dipsas gokool has plates or shields. (8) The green tree viper (Trimeresurus anamallcnsis) is one of the family of Crotalidæe or pit vipers, so named from the pit or cavity beneath the eye and the nostril, of which family the terrible rattlesnake of America is a member. In Inclia there are eight species of Trimeresuri, but up to the present only one has been found in Bombay, though it has been stated that another species, T. strigatus has been seen far up the country. (9) The headquarters of the Hypnale nera, or Carawala, are in Ceylon, but it is commonly found along the Malabar coast.

These classes include all the poisonous land-srakes. All the true sea-snakes are poisonous, and of these, amongst others, the following are in the Bombay collection: Hydrophis niadema, Hydrophis robusta, Hydrophis curta, Hydrophis an ifasciatus, Hydrophis Phitsoni, Hydrophis Guntheri, Hydronlits Lindsayi, Hydrophis chloris, Enrthydrina bengalensis, Pelamis bicolor.

\section{SCIENTIFIC SERIALS.}

Rendiconti del Reale Instituto Lombardo, May. - Foraminifera of Mount S. Colombano Lodigiano, by Dr. tirnesto Mariani. A classified list is given of these organisms, collected chiefly by Profs. Maggi and Balsamo Cuvelli in the district stretching from the right bank of the Lambro to within a few miles of the P'o. The prevalence of Miliolide and allied forms shows that this fauna, which mostly still survives in the surrounding seas, flourished in the warm shallow waters which at a remote epoch flooded the plains of Lombardy. - On the use of the lucimeter in agriculture, by Prof. Giovanni Cantoni. The author's recent experiments with this instrument, first designed by Bellani, show that it is calculated to render great service to husbandry in combination with the thermometer and psycrometer.-Alberto Brambilla continues his paper on a certain class of algebraic surfaces; and Prof. A. Scarenzio has some remarks on the therapeutic properties of the arsenical thermal waters of Acquarossa, near Biasca, on the old St. Gothard road in the Canton of Ticino.

June 7.- On the normal curves of genus $p$ of various spaces, by Prof. E. Bertini. Clifford's fundamental theorem is here established by a more synthetic method than any hitherto publi:hed demonstrations. The theorem itself (Philosophic Transactions, 1878, p. $68 \mathrm{I}$ ) is here announced in the following modified form :-A curve of genus $p$ and order $n>2 p-2$ cannot belong to a space of more than $n-p$ dimensions. - On the proposed sanitary legislation for Italv, by D. C. Zucchi. A calculation is made that by the adoption of such measures as are enforced by the Local Government Boards in Great Britain, the average mortality of the population might be reduced from over 27 to under 20 per thousand. This is shown to be equivalent to the rescue of 100,000 lives, whose labour for 300 working days represents an annual sum of nearly $£ 5$, oco, ooo at present lost to the nation.- Meteorological observations made at the Royal Observatory of Brera, Milan, for the month of May.

\section{SOCIETIES AND ACADEMIES. LONDON.}

Royal Society, June I4.- "The Minimum-point of Change of Potential of a Voitaic Couple." By Dr. G. Gore, F.R.S.

In this communication is described the following very simple method of detecting the influence of the minimum proportion of 